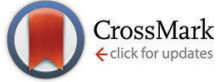

Cite this: J. Mater. Chem. C, 2016 4, 4380

Received 25th February 2016, Accepted 21st April 2016

DOI: $10.1039 / c 6 t c 00802 j$

www.rsc.org/MaterialsC

\section{Novel persistent phosphors of lanthanide- chromium co-doped yttrium aluminum gallium garnet: design concept with vacuum referred binding energy diagram $\dagger$}

\author{
Jian Xu, Jumpei Ueda and Setsuhisa Tanabe*
}

We have developed $\mathrm{Pr}^{3+}-\mathrm{Cr}^{3+}$ and $\mathrm{Tb}^{3+}-\mathrm{Cr}^{3+}$ co-doped $\mathrm{Y}_{3} \mathrm{Al}_{2} \mathrm{Ga}_{3} \mathrm{O}_{12}$ (YAGG) persistent phosphors with orange $\left(\mathrm{Pr}^{3+}\right)$ and light green $\left(\mathrm{Tb}^{3+}\right)$ persistent luminescence. The duration of their persistent luminance (of $0.32 \mathrm{mcd} \mathrm{m}^{-2}$ ) can last up to about $8 \mathrm{~h}$ and $12 \mathrm{~h}$, respectively. On the other hand, the persistent luminescence intensities of $\mathrm{Nd}^{3+}-\mathrm{Cr}^{3+}$ and $\mathrm{Dy}^{3+}-\mathrm{Cr}^{3+} \mathrm{Co}$-doped YAGG samples are much weaker than those of the $\mathrm{Pr}^{3+}-\mathrm{Cr}^{3+}$ and $\mathrm{Tb}^{3+}-\mathrm{Cr}^{3+}$ co-doped ones, and the dominant persistent luminescence is mainly due to the deep-red transition of $\mathrm{Cr}^{3+}$. The mechanisms of different persistent luminescence behaviors of these four samples can be explained by the vacuum referred binding energy (VRBE) diagram of lanthanide ions in the YAGG host. The stability of hole traps at the ground states of $\mathrm{Pr}^{3+}, \mathrm{Nd}^{3+}, \mathrm{Tb}^{3+}$ and $\mathrm{Dy}^{3+}$ ions and the possibility to collaborate with $\mathrm{Cr}^{3+}$ electron traps to induce persistent luminescence are discussed in detail.

\section{Introduction}

Persistent luminescence (PersL), also denoted as "glow-in-the-dark", is a specific type of luminescence that can last for seconds, minutes or even hours, usually at room temperature (RT), after ceasing excitation sources. ${ }^{1-3}$ It has been over 20 years since the new generation green persistent phosphor, $\mathrm{SrAl}_{2} \mathrm{O}_{4}: \mathrm{Eu}^{2+}-\mathrm{Dy}^{3+}$ (SAO:Eu-Dy) was reported and successfully commercialized for safety signage applications, such as emergency exit signs in buildings and guiding strips in the aisles of airplanes. ${ }^{4-10}$ Until now, despite the fast development and considerable research on persistent phosphors after this significant discovery, the detailed mechanism of PersL is still an open question. The most acceptable mechanism can be qualitatively explained by an electron trappingdetrapping process as follows: when persistent phosphors are excited by ultraviolet (UV) light (visible light in rare cases), electron-hole $(\mathrm{e}-\mathrm{h})$ pairs are generated and the excited electrons, through the conduction band (CB), are captured by electron traps; this process is usually called the trapping process. The

Graduate School of Human and Environmental Studies, Kyoto University, Kyoto 606-8501, Japan. E-mail: tanabe.setsuhisa.4v@kyoto-u.ac.jp; Tel: +81-75-753-6832

$\dagger$ Electronic supplementary information (ESI) available. See DOI: 10.1039/c6tc00802j stored electrons are then released by thermal stimulation to the CB (detrapping process) and re-combined with holes, resulting in PersL. During a series of processes, "trap depth", which represents the energy gap between the bottom of the $\mathrm{CB}$ and the electron trap, is crucial since it determines the behavior of PersL, such as initial emission intensity and luminescence duration. The nature of electron traps, such as type, distribution, and energy level location has been extremely well studied; however, there are few reports concerning the role of the other re-combination part, the hole. ${ }^{11-14}$ Similar to electron traps whose energy levels are located below the bottom of the CB, the energy levels of hole traps should also be located above the top of the valence band (VB). Therefore, the determination or even prediction of the energy levels of the doping ions in a host, whether they can be selected as electron traps and/or hole traps, is definitely important for designing novel persistent phosphors.

Recently, we reported garnet persistent phosphors of $\mathrm{Ce}^{3+}, \mathrm{Cr}^{3+}$ co-doped $\mathrm{Y}_{3} \mathrm{Al}_{5-x} \mathrm{Ga}_{x} \mathrm{O}_{12}$ (YAGG:Ce-Cr), in which $\mathrm{Cr}^{3+}$ acts as an efficient electron trap with ideal trap depth at $x=3$ for $\mathrm{Ce}^{3+}$ PersL at RT. ${ }^{15-17}$ The enhanced persistent luminance of the YAGG:Ce-Cr $(x=3)$ transparent ceramic persistent phosphor at $60 \mathrm{~min}$ after ceasing blue excitation could reach 88 mcd $\mathrm{m}^{-2}$, which is over three times higher than that of the compacted pellet made of commercial SAO:Eu-Dy powder $\left(25 \mathrm{mcd} \mathrm{m}^{-2}\right) \cdot{ }^{18}$ On the other hand, we also developed $\mathrm{Cr}^{3+}$ singly-doped YAGG (YAGG:Cr) persistent phosphors with a similar garnet matrix showing deepred PersL $(\sim 690 \mathrm{~nm})$, in which $\mathrm{Cr}^{3+}$ ions act both as emitting centers and trap centers. ${ }^{19,20}$ The persistent radiance (in units of $\left.\mathrm{mW} \mathrm{sr}{ }^{-1} \mathrm{~m}^{-2}\right)$ of the optimized composition $(x=3)$ was even higher than that of the $\mathrm{ZnGa}_{2} \mathrm{O}_{4}: \mathrm{Cr}^{3+}$ persistent phosphor, which is widely used for in vivo bio-imaging applications. ${ }^{3,21-25}$

\section{Choice of lanthanide candidates in the YAGG host}

The successful discovery of these $\mathrm{Cr}^{3+}$ singly- and co-doped YAGG persistent phosphors ${ }^{15,19}$ motivated us to design improved ones 


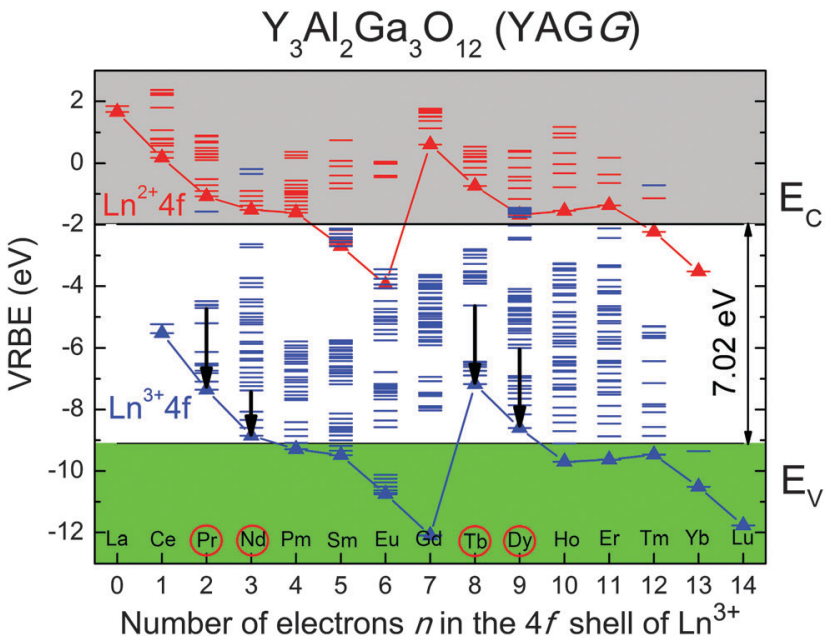

Fig. 1 The VRBE diagram of divalent and trivalent lanthanide ions in the YAGG $(G a=3)$ host.

with the help of theoretical predictions, especially the energy level locations of lanthanide ions in a specific host, due to their wide adoption as emission centers and/or trap centers for PersL. Vacuum referred binding energy (VRBE) diagrams of 15 lanthanides, proposed by Dorenbos, ${ }^{26-32}$ provide a strong predicting power since the characteristic variation in electron and hole trapping depths of lanthanide ions is given by the shapes of the two zigzag curves representing the ground states of divalent and trivalent lanthanide ions. The zigzag shapes of the two curves remain almost unchanged in different hosts, due to the shielding effect of $5 s^{2}$ and $5 p^{6}$ orbitals on the $4 \mathrm{f}$ orbitals. Once the binding energy of the ground state for one lanthanide ion relative to the $\mathrm{CB}$ or $\mathrm{VB}$ is determined, those of the $4 \mathrm{f}$ levels of all other lanthanides can be estimated fairly well by constructing this diagram.

According to the VRBE diagram of the YAGG host $^{16}$ shown in Fig. 1, besides $\mathrm{Ce}^{3+}$, there are four other trivalent lanthanides $\left(\mathrm{Pr}^{3+}, \mathrm{Nd}^{3+}, \mathrm{Tb}^{3+}, \mathrm{Dy}^{3+}\right)$ whose ground states are located above the top of the VB, indicating that they can be selected as potential candidates for hole traps. Therefore, in this work, $\mathrm{Pr}^{3+}-\mathrm{Cr}^{3+}$, $\mathrm{Nd}^{3+}-\mathrm{Cr}^{3+}, \mathrm{Tb}^{3+}-\mathrm{Cr}^{3+}, \mathrm{Dy}^{3+}-\mathrm{Cr}^{3+}$ co-doped YAGG phosphors were prepared and their feasibility for PersL are discussed based on this diagram.

\section{Experimental section}

Transparent ceramics of $\mathrm{Y}_{2.985} \mathrm{Pr}_{0.015} \mathrm{Al}_{1.999} \mathrm{Cr}_{0.001} \mathrm{Ga}_{3} \mathrm{O}_{12}$ (YAGG: $\mathrm{Pr}-\mathrm{Cr}$ ), $\mathrm{Y}_{2.97} \mathrm{Nd}_{0.03} \mathrm{Al}_{1.999} \mathrm{Cr}_{0.001} \mathrm{Ga}_{3} \mathrm{O}_{12}$ (YAGG:Nd-Cr), $\mathrm{Y}_{2.97} \mathrm{~Tb}_{0.03^{-}}$ $\mathrm{Al}_{1.999} \mathrm{Cr}_{0.001} \mathrm{Ga}_{3} \mathrm{O}_{12}$ (YAGG:Tb-Cr), and $\mathrm{Y}_{2.985} \mathrm{Dy}_{0.015} \mathrm{Al}_{1.999} \mathrm{Cr}_{0.001}{ }^{-}$ $\mathrm{Ga}_{3} \mathrm{O}_{12}$ (YAGG:Dy-Cr) were fabricated by a solid-state reaction method and vacuum sintering. $\mathrm{Y}_{2} \mathrm{O}_{3}, \mathrm{Al}_{2} \mathrm{O}_{3}, \mathrm{Ga}_{2} \mathrm{O}_{3} \operatorname{Pr}_{6} \mathrm{O}_{11}$, $\mathrm{Nd}_{2} \mathrm{O}_{3}, \mathrm{~Tb}_{4} \mathrm{O}_{7}$ and $\mathrm{Dy}_{2} \mathrm{O}_{3}$ with $4 \mathrm{~N}$ purity, and $\mathrm{Cr}_{2} \mathrm{O}_{3}$ with $3 \mathrm{~N}$ purity were used as raw materials. The starting powder was mixed by the ball milling method, with anhydrous alcohol, for several hours. The powder mixture was dried at $80{ }^{\circ} \mathrm{C}$ for $36 \mathrm{~h}$ and compacted to form a ceramic green body $[\phi 20 \mathrm{~mm} \times(2-3) \mathrm{mm}]$ under uniaxial pressure of $50 \mathrm{MPa}$, and finally sintered at
$1600-1650{ }^{\circ} \mathrm{C}$ for $10-20 \mathrm{~h}$ under vacuum. The as-sintered samples were double-mirror polished to a thickness of $1.5 \pm 0.1 \mathrm{~mm}$ using a copper plate and diamond slurry. The transparent ceramics of $\mathrm{Y}_{2.985} \mathrm{Ce}_{0.015} \mathrm{Al}_{1.999} \mathrm{Cr}_{0.001} \mathrm{Ga}_{3} \mathrm{O}_{12} \quad(\mathrm{YAGG}: \mathrm{Ce}-\mathrm{Cr})^{18}$ and $\mathrm{Y}_{3} \mathrm{Al}_{1.99} \mathrm{Cr}_{0.01} \mathrm{Ga}_{3} \mathrm{O}_{12}$ (YAGG:Cr) ${ }^{19}$ prepared by the same method were used as reference samples. All the as-prepared samples were confirmed to be single phase (ICPDS: No. 089-6660) by XRD measurement (see Fig. S1, ESI $\dagger$ ).

Photoluminescence (PL) and PersL spectra of the YAGG samples were measured at $25{ }^{\circ} \mathrm{C}$ by a Si CCD spectrometer (QE65-Pro, Ocean Optics) and calibrated by a standard halogen lamp (SCL-600, Labsphere). A $300 \mathrm{~W}$ Xe-lamp (MAX-302, Asahi Spectra) with a UV mirror module $(250-400 \mathrm{~nm})$ was used as the excitation source for thermoluminescence (TL) two-dimensional (2D) plot measurements (see the schematic illustration of measurement setup in Fig. S2, ESI $\dagger$ ). The ceramic sample was set in a cryostat (Helitran LT3, Advanced Research Systems) to control the temperature and firstly illuminated by UV light at $150 \mathrm{~K}$ for $10 \mathrm{~min}$, then heated up to $550 \mathrm{~K}$ at a rate of $10 \mathrm{~K} \mathrm{~min}^{-1}$ at $10 \mathrm{~min}$ after ceasing the illumination. The TL signals were recorded by a PMT detector (R11041, Hamamatsu Photonics \& Co. Ltd,) covered with $350 \mathrm{~nm}$ short-cut and $750 \mathrm{~nm}$ long-cut filters. The CCD spectrometer was operated simultaneously with the TL measurement to monitor the emission spectra at different temperatures. All persistent luminescence decay curves of the samples, after being excited for 5 min by the Xe-lamp with the UV module, were measured at $25{ }^{\circ} \mathrm{C}$ using the same PMT detector. The decay curves were then calibrated to the absolute intensity (luminance, in units of $\mathrm{mcd} \mathrm{m}^{-2}$ ) using a radiance meter (Glacier X, B\&W Tek Inc.). Photographs of the samples were taken with a digital camera (EOS kiss X5, Canon) under the same setting conditions: exposure time $-0.1 \mathrm{~s}$, ISO value -1600 , aperture value ( $F$ value) - 5.0.

\section{Results}

\subsection{PL and PersL spectra}

Fig. 2(a1)-(d1) show the PL spectra of the YAGG:Ln-Cr ( $L n=$ Pr, $\mathrm{Tb}, \mathrm{Nd}$, Dy) phosphors excited by their respective excitation wavelengths. The typical $\mathrm{f}-\mathrm{f}$ transitions due to $\operatorname{Pr}^{3+}:{ }^{3} \mathrm{P}_{\mathrm{J}} \rightarrow{ }^{3} \mathrm{H}_{4,5}$, ${ }^{1} \mathrm{D}_{2} \rightarrow{ }^{3} \mathrm{H}_{4} ; \mathrm{Tb}^{3+}:{ }^{5} \mathrm{D}_{3},{ }^{5} \mathrm{D}_{4} \rightarrow{ }^{7} \mathrm{~F}_{\mathrm{J}} ; \mathrm{Nd}^{3+}:{ }^{4} \mathrm{~F}_{3 / 2} \rightarrow{ }^{4} \mathrm{I}_{9 / 2}$ and $\mathrm{Dy}^{3+}:$ ${ }^{4} \mathrm{~F}_{9 / 2} \rightarrow{ }^{6} \mathrm{H}_{15 / 2},{ }^{6} \mathrm{H}_{13 / 2},{ }^{6} \mathrm{H}_{11 / 2},{ }^{6} \mathrm{H}_{9 / 2}$ were observed in YAGG: $\mathrm{Pr}-\mathrm{Cr}, \mathrm{YAG} G: \mathrm{Tb}-\mathrm{Cr}, \mathrm{YAG} G$ :Nd-Cr and YAGG:Dy-Cr samples, respectively. Besides, $\mathrm{Cr}^{3+}$ luminescence bands were also observed in the YAGG:Pr-Cr and YAGG:Tb-Cr samples since the excitation wavelengths for $\operatorname{Pr}^{3+}(244 \mathrm{~nm})$ and $\mathrm{Tb}^{3+}(235 \mathrm{~nm})$ match well with the excitation band of $\mathrm{Cr}^{3+}:{ }^{4} \mathrm{~A}_{2}\left({ }^{4} \mathrm{~F}\right) \rightarrow{ }^{4} \mathrm{~T}_{1}\left({ }^{4} \mathrm{P}\right)$. However, the excitation wavelengths for $\mathrm{Nd}^{3+}(354 \mathrm{~nm})$ and $\mathrm{Dy}^{3+}(353 \mathrm{~nm})$ did not match the excitation bands of $\mathrm{Cr}^{3+} ;{ }^{19,20}$ therefore, the typical $\mathrm{Cr}^{3+}$ bands, including " $R$-line": ${ }^{2} \mathrm{E}\left({ }^{2} \mathrm{G}\right) \rightarrow$ ${ }^{4} \mathrm{~A}_{2}\left({ }^{4} \mathrm{~F}\right)$ and its phonon sidebands (PSBs), were not observed in the YAGG:Nd-Cr sample, but still existed in the YAGG:Dy-Cr sample. This is mainly attributed to the energy transfer from $\mathrm{Dy}^{3+}:{ }^{4} \mathrm{~F}_{9 / 2}$ to $\mathrm{Cr}^{3+}:{ }^{4} \mathrm{~T}_{2}\left({ }^{4} \mathrm{~F}\right)$ followed by $R$-line luminescence of $\mathrm{Cr}^{3+}$. 

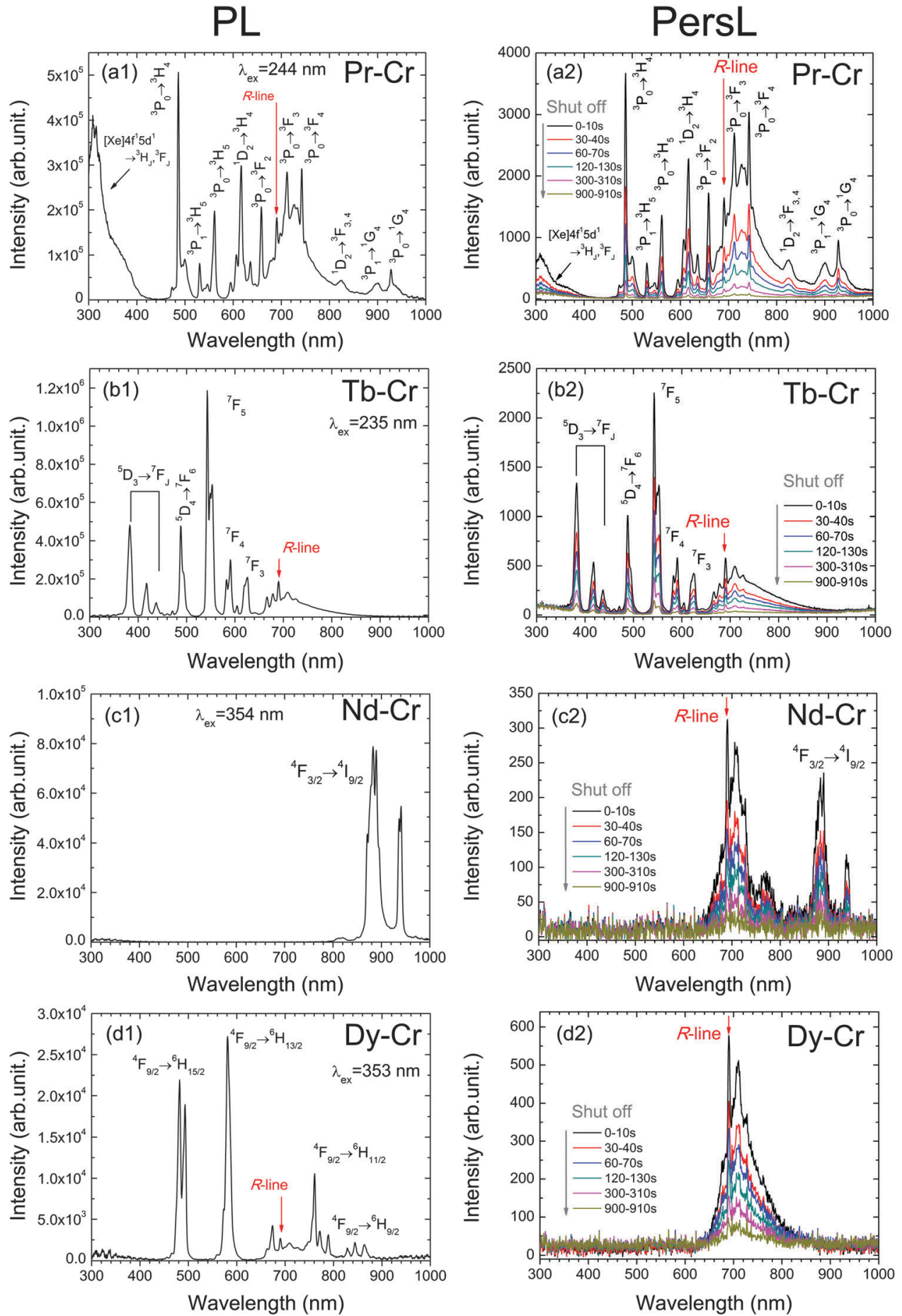

Fig. 2 PL spectra of YAGG persistent phosphors co-doped with (a1) $\operatorname{Pr}-\mathrm{Cr}\left(\lambda_{\mathrm{ex}}=244 \mathrm{~nm}\right),(\mathrm{b} 1) \mathrm{Tb}-\mathrm{Cr}\left(\lambda_{\mathrm{ex}}=235 \mathrm{~nm}\right),(\mathrm{c} 1) \mathrm{Nd}-\mathrm{Cr}\left(\lambda_{\mathrm{ex}}=354 \mathrm{~nm}\right)$, (d1) $\mathrm{Dy}-\mathrm{Cr}\left(\lambda_{\mathrm{ex}}=353 \mathrm{~nm}\right)$. The corresponding PersL spectra (integration time: $10 \mathrm{~s}$ ) of (a2) Pr-Cr, (b2) Tb-Cr, (c2) Nd-Cr, (d2) Dy-Cr, after ceasing UV (250-400 nm) illumination for $5 \mathrm{~min}$.

After ceasing the UV (250-400 nm) excitation, the corresponding PersL spectra of the four YAGG persistent phosphors were recorded at different times, shown in Fig. 2(a2)-(d2). The shapes of the PL and PersL spectra are nearly identical in the YAGG:Pr-Cr and YAGG:Tb-Cr samples, suggesting that the emission centers due to $\mathrm{Pr}^{3+}$ and $\mathrm{Tb}^{3+}$ are the same under and after excitation. However, the PersL spectra of the YAGG:Nd-Cr and YAGG:Dy-Cr samples are quite different from their PL spectra, in which PersL from $\mathrm{Cr}^{3+}$ is mainly dominant, and their PersL intensities are much weaker than those of the YAGG:Pr-Cr and YAGG:Tb-Cr samples.

\subsection{Persistent luminescence decay curves}

Fig. 3(a)-(c) show the photographs of YAGG:Ln-Cr $(L n=\mathrm{Ce}, \mathrm{Pr}$, $\mathrm{Nd}, \mathrm{Tb}, \mathrm{Dy})$ transparent ceramic persistent phosphors together 

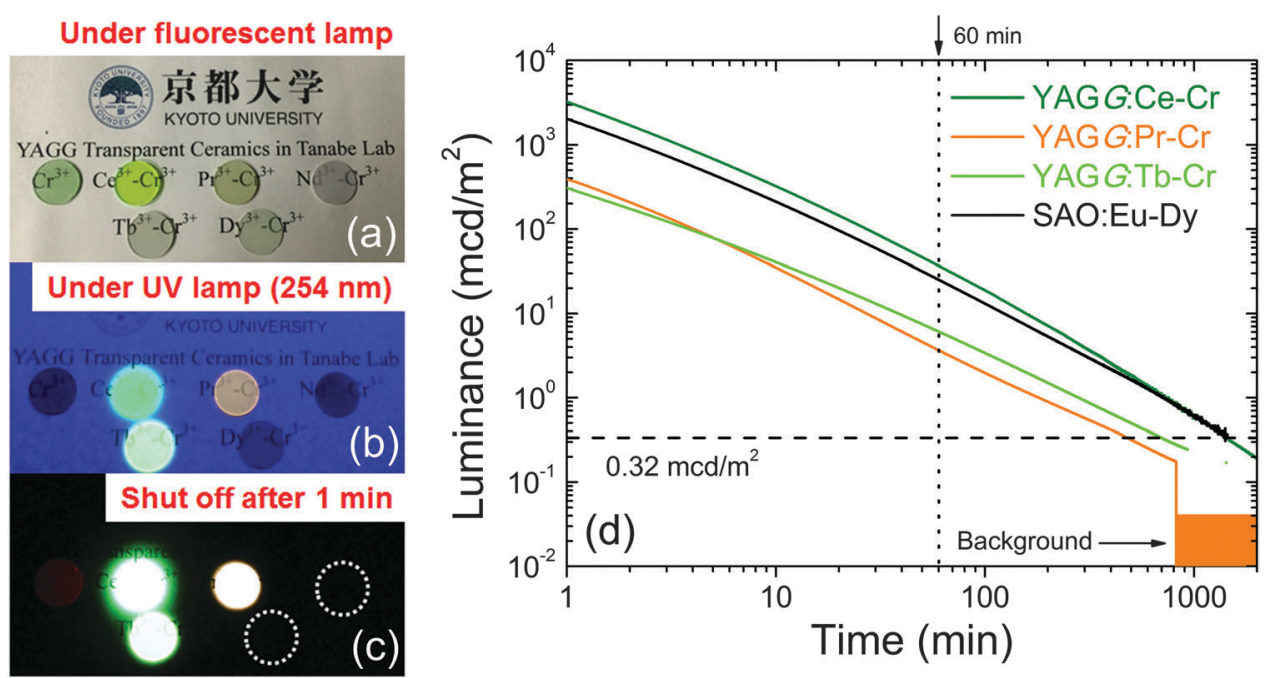

Fig. 3 Images of $\mathrm{Cr}$ singly- and $\mathrm{Ce}-\mathrm{Cr}, \mathrm{Pr}-\mathrm{Cr}, \mathrm{Nd}-\mathrm{Cr}, \mathrm{Tb}-\mathrm{Cr}$, Dy- $\mathrm{Cr}$ co-doped $\mathrm{YAGG}$ transparent ceramic persistent phosphors (a) under fluorescent lamp (b) under UV (254 nm) lamp (c) at 1 min after shutting off the light. (d) Persistent luminance of $\mathrm{Ce}-\mathrm{Cr}$, $\mathrm{Pr}-\mathrm{Cr}$, Tb-Cr co-doped YAGG transparent ceramics compared with that of the commercial $\mathrm{SrAl}_{2} \mathrm{O}_{4}$ : Eu-Dy persistent phosphor, after ceasing excitation.

with one reference sample, YAGG:Cr, under and after UV $(254 \mathrm{~nm})$ excitation. All the samples show optical transparency, through which the letters below the samples can be clearly recognized by the naked eye. After ceasing the excitation, $\mathrm{Ce}-\mathrm{Cr}, \mathrm{Pr}-\mathrm{Cr}$, and $\mathrm{Tb}-\mathrm{Cr}$ co-doped samples exhibit bright PersL due to $\mathrm{Ce}^{3+}$ (green), $\operatorname{Pr}^{3+}$ (orange) and $\mathrm{Tb}^{3+}$ (light green), respectively. The color coordinates of PersL in the CIE 1931 chromaticity diagram are $(0.295,0.553)$ for YAGG:Ce-Cr, $(0.439,0.367)$ for YAGG:Pr-Cr, and $(0.313,0.454)$ for YAGG:Tb-Cr samples (see Fig. S3, ESI $\dagger$ ). On the other hand, the $\mathrm{Nd}-\mathrm{Cr}$, Dy-Cr co-doped samples [white circles in Fig. 3(c)] showed very weak deep-red PersL (too weak to be recorded by the camera) due to $\mathrm{Cr}^{3+}$, which was also observed in the YAGG:Cr reference sample.

The persistent luminescence decay curves (in luminance units) of the YAGG:Pr-Cr and YAGG:Tb-Cr samples, after ceasing UV (250-400 nm) illumination for $5 \mathrm{~min}$, are shown in Fig. 3(d). The decay profiles of the YAGG:Ce-Cr phosphor ${ }^{18}$ and the compacted pellet made of the SAO:Eu-Dy commercial phosphor (LumiNovaGLL300FFS, Nemoto \& Co. Ltd, $)^{15}$ are also plotted as references. The luminance values at $60 \mathrm{~min}$ after ceasing the excitation were $35 \mathrm{mcd} \mathrm{m}^{-2}$ for YAGG:Ce-Cr, $3.7 \mathrm{mcd} \mathrm{m}^{-2}$ for YAGG:Pr-Cr, $6.1 \mathrm{mcd} \mathrm{m}^{-2}$ for YAGG:Tb-Cr and $25 \mathrm{mcd} \mathrm{m}^{-2}$ for SAO:Eu-Dy samples. Persistent luminance durations, to reach a value of $0.32 \mathrm{mcd} \mathrm{m}^{-2}$, were around $1469 \mathrm{~min}$ for YAGG:Ce-Cr, $499 \mathrm{~min}$ for YAGG:Pr-Cr, and 729 min for YAGG:Tb-Cr samples. Note that the luminance of $0.32 \mathrm{mcd} \mathrm{m} \mathrm{m}^{-2}$ is the minimum value commonly used by the safety signage industry (about 100 times the sensitivity of the dark-adapted eye). ${ }^{2}$

\subsection{TL glow curves}

Fig. 4 shows the contour plots (2D mapping) of TL glow curves of the YAGG: $L n-\mathrm{Cr}(L n=\mathrm{Pr}, \mathrm{Tb}, \mathrm{Nd}$, Dy) samples in order to see what kind of emission contributes to the TL glow peak at different temperatures. From the plots of the YAGG:Pr-Cr and YAGG:Tb-Cr samples in (a) and (b), it can be seen that at increased temperatures, the TL spectra are simply composed of two luminescence centers from $\mathrm{Pr}^{3+} / \mathrm{Tb}^{3+}$ and $\mathrm{Cr}^{3+}$, which agree well with their PersL spectra in Fig. 2(a2) and (b2). The intense TL glow peaks of the two samples are located at around RT so that they can show intense PersL at RT. However, in the Nd-Cr and Dy-Cr co-doped samples given in (c) and (d), the PersL intensities are much weaker than those of the $\mathrm{Pr}-\mathrm{Cr}$ and $\mathrm{Tb}-\mathrm{Cr}$ co-doped ones, in which the TL spectra are mainly composed of the broad band luminescence from $\mathrm{Cr}^{3+}$ (origin of PersL from $\mathrm{Nd}^{3+}$ will be discussed later in the next section). Especially for the YAGG:Dy-Cr sample, no sharp $\mathrm{f}-\mathrm{f}$ transitions of $\mathrm{Dy}^{3+}$ are observed at any temperatures, which indicates that $\mathrm{Dy}^{3+}$ ions do not contribute to the PersL.

\section{Discussion}

According to the obtained results of the four YAGG:Ln-Cr $(L n=\mathrm{Pr}, \mathrm{Nd}, \mathrm{Tb}, \mathrm{Dy})$ phosphors, they can be approximately divided into three groups: (i) $\mathrm{Pr}-\mathrm{Cr}$ and $\mathrm{Tb}-\mathrm{Cr}$ co-doped samples showing bright PersL mainly from $\mathrm{Pr}^{3+}$ and $\mathrm{Tb}^{3+}$ (ii) Dy-Cr co-doped sample showing weak PersL only from $\mathrm{Cr}^{3+}$. (iii) $\mathrm{Nd}-\mathrm{Cr}$ co-doped sample showing weak PersL both from $\mathrm{Cr}^{3+}$ and $\mathrm{Nd}^{3+}$.

It is worth noting that human eyes are most sensitive to green and yellow emission; less sensitive to violet, blue, and red emission; UV and near-infrared (NIR) emission are totally invisible. ${ }^{33}$ The photopic vision, which is mediated by the cone cells in human eyes, allows color perception and shows a broad band sensitivity curve (from 380 to $780 \mathrm{~nm}$ ), which peaks at $555 \mathrm{~nm}$ with $683 \mathrm{~lm} \mathrm{~W}^{-1}$ luminous efficacy. The line emissions due to $\operatorname{Pr}^{3+}:{ }^{3} \mathrm{P}_{\mathrm{J}(=0,1,2)} \rightarrow{ }^{3} \mathrm{H}_{4,5},{ }^{1} \mathrm{D}_{2} \rightarrow{ }^{3} \mathrm{H}_{4}$, and $\mathrm{Tb}^{3+}:{ }^{5} \mathrm{D}_{4} \rightarrow$ ${ }^{7} \mathrm{~F}_{\mathrm{J}(\mathrm{J}=6,5,4,3)}$ in $\mathrm{YAGG}: \mathrm{Pr}-\mathrm{Cr}$ and $\mathrm{YAGG}$ :Tb-Cr samples match well with the sensitivity curve of photopic vision (see Fig. S4, ESI $\dagger$ ). However, the luminous efficacy is almost zero in the deep-red 

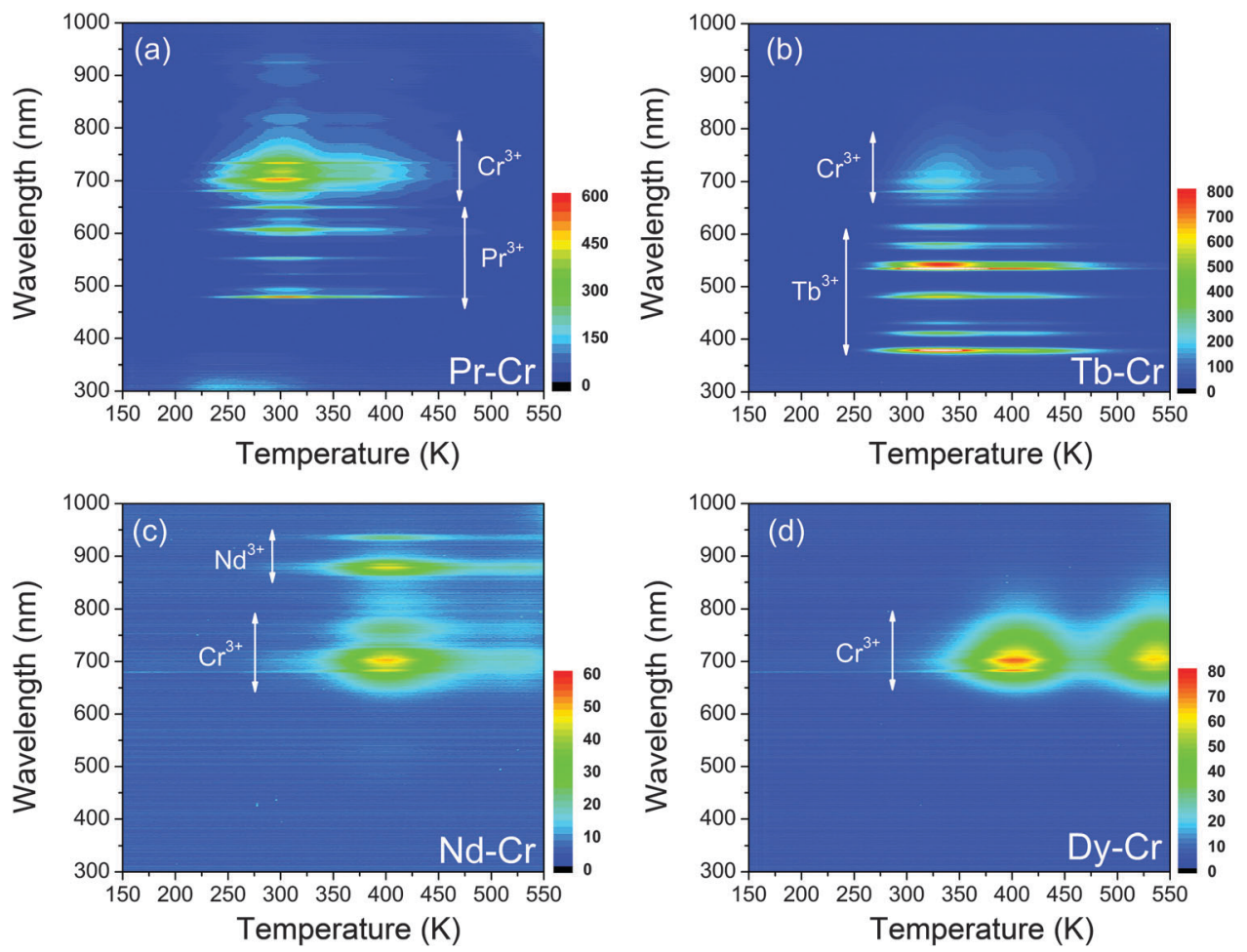

Fig. 4 Wavelength-temperature $(\lambda-T)$ contour plots of the (a) YAGG: $P r-C r$ (b) YAGG: $\mathrm{Tb}-\mathrm{Cr}$ (c) YAGG:Nd-Cr (d) YAGG:Dy-Cr transparent ceramic persistent phosphors.

to NIR region, so that PersL from $\mathrm{Cr}^{3+}$ is difficult to be captured by human eyes.

In $\mathrm{Ln}^{3+}-\mathrm{Cr}^{3+}$ co-doped garnets, the PersL process usually occurs in four steps according to the electron trapping-detrapping model (the charging energy is assumed to be high enough to excite the electron into the $\mathrm{CB}$ ):

$$
\begin{aligned}
& (\mathrm{e}-\mathrm{h}) \stackrel{h \nu}{\longrightarrow} \mathrm{e}^{-}+\mathrm{h}^{+} \quad \text { [electron }- \text { hole generation] } \\
& \mathrm{Ln}^{3+}+\mathrm{h}^{+} \rightarrow \mathrm{Ln}^{4+} \text { or }\left(\mathrm{Ln}^{3+}+\mathrm{h}^{+}\right) \text {[hole trapping] } \\
& \mathrm{Cr}^{3+}+\mathrm{e}^{-} \rightarrow \mathrm{Cr}^{2+} \text { or }\left(\mathrm{Cr}^{3+}+\mathrm{e}^{-}\right) \text {[electron trapping] }
\end{aligned}
$$

$\mathrm{Ln}^{4+}$ or $\left(\mathrm{Ln}^{3+}+\mathrm{h}^{+}\right)+\mathrm{e}^{-} \rightarrow\left(\mathrm{Ln}^{3+}\right)^{*}$ [electron de-trapping from $\mathrm{Cr}^{2+}$ or $\left(\mathrm{Cr}^{3+}+\mathrm{e}^{-}\right)$leading to $\mathrm{Ln}^{3+}$ in an excited state]

$$
\left(\operatorname{Ln}^{3+}\right)^{*} \rightarrow \mathrm{Ln}^{3+}+h \nu \text { [radiative transition] }
$$

When $\mathrm{e}^{-}$and $\mathrm{h}^{+}$are generated under excitation (step 1), the $\mathrm{Cr}^{3+}$ ion acts as an efficient electron trap capturing one electron to give $\mathrm{Cr}^{2+}$ or $\left(\mathrm{Cr}^{3+}+\mathrm{e}^{-}\right),{ }^{16,19}$ and the $\mathrm{Ln}^{3+}$ ion acts as a hole trap to give $\mathrm{Ln}^{4+}$ or $\left(\mathrm{Ln}^{3+}+\mathrm{h}^{+}\right)$(step 2). The $\mathrm{Ln}^{4+}\left(\mathrm{Ln}^{3+}+\mathrm{h}^{+}\right)$ion is a re-combination center for the electron that is released from the existing electron trap center $\mathrm{Cr}^{2+}\left(\mathrm{Cr}^{3+}+\mathrm{e}^{-}\right)$on heating, predominating the origin of the respective TL glow peak. During the thermal release of the electron from the $\mathrm{Cr}^{2+}\left(\mathrm{Cr}^{3+}+\mathrm{e}^{-}\right)$trap center with the subsequent trapping on the $\mathrm{Ln}^{4+}\left(\mathrm{Ln}^{3+}+\mathrm{h}^{+}\right)$center, the excited state of the $\left(\mathrm{Ln}^{3+}\right)^{*}$ ion appears in the process of re-combination (step 3). The radiative transition from $\left(\mathrm{Ln}^{3+}\right)^{*}$ gives typical PersL of $\mathrm{Ln}^{3+}$ (step 4).
The above mechanism provides a good explanation for the PersL behaviors of YAGG:Pr-Cr and YAGG:Tb-Cr samples. According to the VRBE diagram of the YAGG host (see Fig. 1), similar to $\mathrm{Ce}^{3+},{ }^{15,16}$ the ground states of $\operatorname{Pr}^{3+}\left({ }^{3} \mathrm{H}_{4}\right)$ and $\mathrm{Tb}^{3+}\left({ }^{7} \mathrm{~F}_{6}\right)$ are located above the top of the $\mathrm{VB}$, with a large energy gap $\left(1.78 \mathrm{eV}\right.$ for $\mathrm{Pr}^{3+} ; 1.96 \mathrm{eV}$ for $\left.\mathrm{Tb}^{3+}\right)$. Therefore, the hole created at $\mathrm{Pr}^{3+} / \mathrm{Tb}^{3+}$ is difficult to move to the VB when compared with moving a photo-induced electron into the CB at RT. As such, $\mathrm{Pr}^{3+} / \mathrm{Tb}^{3+}$ ions can be a stable hole trap $\left(\mathrm{Pr}^{4+} / \mathrm{Tb}^{4+}\right.$ or $\left.\mathrm{Pr}^{3+} / \mathrm{Tb}^{3+}+\mathrm{h}^{+}\right)$, collaborating with the $\mathrm{Cr}^{3+}$ electron trap to induce the long PersL. Furthermore, similar to the YAGG:Ce-Cr persistent phosphors, ${ }^{15,16}$ the PersL behaviors of the YAGG:Pr-Cr and YAGG:Tb-Cr persistent phosphors, such as initial emission intensity, luminescence duration and adapting temperature can also be made tunable by changing the $\mathrm{Ga}^{3+}$ substitution content in the tetrahedral and/or octahedral sites of the YAGG host (taking YAGG:Pr-Cr orange persistent phosphors as an example, see Fig. S5 and Table S1, ESI $\dagger$ ).

However, the energy gap between the ground state of $\mathrm{Dy}^{3+}\left({ }^{6} \mathrm{H}_{15 / 2}\right)$ and the top of the VB is too small $(0.54 \mathrm{eV})$ as described in the diagram. Once a photo-induced hole is captured by $\mathrm{Dy}^{3+}$, it will immediately escape into the VB so that it is quite difficult to form a stable hole trap at $\mathrm{Dy}^{3+}$ to be form $\mathrm{Dy}^{4+}$ or $\left(\mathrm{Dy}^{3+}+\mathrm{h}^{+}\right)$at RT. As a consequence, the re-combination of $\mathrm{e}-\mathrm{h}$ pairs may occur via a non-radiative approach so that PersL from the $\left(\mathrm{Dy}^{3+}\right)^{*}$ state is totally quenched (see Fig. 2(d2) and 4d). In this special case, $\mathrm{Cr}^{3+}$ ions take part in the PersL process, since under UV illumination $\mathrm{Cr}^{3+}$ itself can act both as a hole trap center to form $\mathrm{Cr}^{4+}\left(\mathrm{Cr}^{3+}+\mathrm{h}^{+}\right)$and an electron trap 
center to form $\mathrm{Cr}^{2+}\left(\mathrm{Cr}^{3+}+\mathrm{e}^{-}\right) \cdot{ }^{19} \mathrm{The}^{\mathrm{Cr}^{4+}}\left(\mathrm{Cr}^{3+}+\mathrm{h}^{+}\right)$ion acts as a re-combination center for the electron that is released from the $\mathrm{Cr}^{2+}\left(\mathrm{Cr}^{3+}+\mathrm{e}^{-}\right)$trap center, followed by PersL due to $\mathrm{Cr}^{3+}$. Considering the small doping concentration of $\mathrm{Cr}^{3+}$ in this work $\left(0.05 \mathrm{~mol} \%\right.$, ten times lower than our previous report $\left.{ }^{19}\right)$, the observed weak PersL from $\mathrm{Cr}^{3+}$ in the YAGG:Dy-Cr sample is quite reasonable.

The PersL mechanism of the YAGG:Nd-Cr sample is more complicated than for other samples. The ground state of $\mathrm{Nd}^{3+}\left({ }^{4} \mathrm{I}_{9 / 2}\right)$ is quite close to the top of the $\mathrm{VB}$ (energy gap: $0.29 \mathrm{eV}$, even smaller than that of $\mathrm{Dy}^{3+}$ ) in the VRBE diagram. This indicates that $\mathrm{Nd}^{3+}$ cannot work as a stable hole trap to form $\mathrm{Nd}^{4+}$ or $\left(\mathrm{Nd}^{3+}+\mathrm{h}^{+}\right)$at RT; however, PersL from $\mathrm{Nd}^{3+}$ is still observed (see Fig. 2(c2) and 4c). This is mainly attributed to the persistent energy transfer from $\mathrm{Cr}^{3+}$ to $\mathrm{Nd}^{3+}$, which is similar to the same process as that in the YAGG host, where it occurs from $\mathrm{Ce}^{3+}$ to $\mathrm{Nd}^{3+} \cdot{ }^{34}$ Since the emission band of the donor $\left(\mathrm{Cr}^{3+}\right)$ matches well with the absorption band of the acceptor $\left(\mathrm{Nd}^{3+}\right)$, resonant energy transfer from $\mathrm{Cr}^{3+}$ to $\mathrm{Nd}^{3+}$ takes place, like that in $\mathrm{Y}_{3} \mathrm{Al}_{5} \mathrm{O}_{12}(\mathrm{YAG})^{35,36}$ (see Fig. S6, ESI $\dagger$ ). Therefore, the persistent energy transfer occurs mainly from $\mathrm{Cr}^{3+}:{ }^{2} \mathrm{E}\left({ }^{2} \mathrm{G}\right)$ to $\mathrm{Nd}^{3+}:{ }^{4} \mathrm{~F}_{7 / 2}$, which is followed by rapid multi-phonon relaxation down to the ${ }^{4} \mathrm{~F}_{3 / 2}$ excited level, and finally induces the sharp PersL bands of $\mathrm{Nd}^{3+}:{ }^{4} \mathrm{~F}_{3 / 2} \rightarrow{ }^{4} \mathrm{I}_{\mathrm{J}}$ located at around $880 \mathrm{~nm}$ and longer wavelengths.

\section{Conclusions}

In summary, based on the VRBE diagram of the YAGG host, $\mathrm{Pr}^{3+}, \mathrm{Nd}^{3+}, \mathrm{Tb}^{3+}, \mathrm{Dy}^{3+}$ ions were selected and co-doped with $\mathrm{Cr}^{3+}$ ions to develop novel persistent phosphors. The energy gaps between the ground states of $\mathrm{Pr}^{3+} / \mathrm{Tb}^{3+}$ and the top of the $\mathrm{VB}$ are large enough so that $\mathrm{Pr}^{3+} / \mathrm{Tb}^{3+}$ ions can form stable hole traps, collaborating with the $\mathrm{Cr}^{3+}$ electron traps to induce long PersL. The duration of the persistent luminance $\left(0.32 \mathrm{mcd} \mathrm{m}^{-2}\right)$ of the YAGG:Pr-Cr and YAGG:Tb-Cr samples due to $\operatorname{Pr}^{3+}$ (orange) and $\mathrm{Tb}^{3+}$ (light green) could reach about $8 \mathrm{~h}$ and $12 \mathrm{~h}$, respectively. However, because of the small energy gaps between the ground states of $\mathrm{Nd}^{3+} / \mathrm{Dy}^{3+}$ and the top of the $\mathrm{VB}, \mathrm{Nd}^{3+} / \mathrm{Dy}^{3+}$ ions cannot act as stable hole traps. Therefore, the persistent luminescence intensities of YAGG:Nd-Cr and YAGG:Dy-Cr samples are quite weak and are dominated mainly by the deep-red transition of $\mathrm{Cr}^{3+}$.

In this paper, we introduced a way to design novel garnet persistent phosphors, based on the knowledge of the energy level diagram of lanthanide dopants. Since lanthanide ions are widely used as emission centers and/or trap centers for PersL, this theoretical prediction diagram can be a useful guide for choosing the proper lanthanide ions, in a more general and convenient manner, to design new storage phosphors in different matrices.

\section{Acknowledgements}

We would like to acknowledge Prof. Pieter Dorenbos from Delft University of Technology, Prof. Bruno. Viana from Chimie-Paris Tech and Prof. Peter A. Tanner from the Hong Kong Institute of Education, who stayed at Kyoto University as visiting professors, for fruitful discussions on persistent phosphors and luminescence mechanisms.

\section{References}

1 K. van den Eeckhout, P. F. Smet and D. Poelman, Materials, 2010, 3, 2536.

2 K. van den Eeckhout, D. Poelman and P. F. Smet, Materials, 2013, 6, 2789.

3 B. Viana, S. K. Sharma, D. Gourier, T. Maldiney, E. Teston, D. Scherman and C. Richard, J. Lumin., 2016, 170, 879.

4 Y. Murayama, N. Takeuchi, Y. Aoki and T. Matsuzawa, US Pat., 5.242.006, 1995.

5 H. Takasaki, S. Tanabe and T. Hanada, J. Ceram. Soc. Jpn., 1996, 104, 322.

6 S. Tanabe and T. Hanada, New Ceramics, 1996, 9(10), 27, in Japanese.

7 T. Matsuzawa, Y. Aoki, N. Takeuchi and Y. Murayama, J. Electrochem. Soc., 1996, 143, 2670.

8 Y. Aoki, Y. Hirata, H. Sasai, T. Ohishi and N. Takeuchi, Japanese Pat., 208948, 1997.

9 F. Clabau, X. Rocquefelte, S. Jobic, P. Deniard, M. H. Whangbo, A. Garcia and T. Le Mercier, Chem. Mater., 2005, 17, 3904.

10 J. Botterman and P. F. Smet, Opt. Express, 2015, 23, A868.

11 K. Chakrabarti, V. K. Mathur, J. F. Rhodes and R. J. Abbundi, J. Appl. Phys., 1988, 64, 1363.

12 A. Lecointre, A. Bessière, A. J. J. Bos, P. Dorenbos, B. Viana and S. Jacquart, J. Phys. Chem. C, 2011, 115, 4217.

13 H. Luo, A. J. J. Bos and P. Dorenbos, J. Phys. Chem. C, 2016, 120, 5916.

14 B. Qu, B. Zhang, L. Wang, R. Zhou, X.-C. Zeng and L. Li, ACS Appl. Mater. Interfaces, 2016, 8, 5439.

15 J. Ueda, K. Kuroishi and S. Tanabe, Appl. Phys. Lett., 2014, 104, 101904.

16 J. Ueda, P. Dorenbos, A. J. J. Bos, K. Kuroishi and S. Tanabe, J. Mater. Chem. C, 2015, 3, 5642.

17 J. Ueda, J. Ceram. Soc. Jpn., 2015, 123, 1059.

18 J. Xu, J. Ueda, K. Kuroishi and S. Tanabe, Scr. Mater., 2015, 102, 47.

19 J. Xu, J. Ueda, Y. Zhuang, B. Viana and S. Tanabe, Appl. Phys. Express, 2015, 8, 042602.

20 Y. Katayama, B. Viana, D. Gourier, J. Xu and S. Tanabe, Opt. Mater. Express, 2016, 6, 1405.

21 A. Bessière, S. Jacquart, K. Priolkar, A. Lecointre, B. Viana and D. Gourier, Opt. Express, 2011, 19(11), 10131.

22 T. Maldiney, A. Bessière, J. Seguin, E. Teston, S. K. Sharma, B. Viana, A. J. J. Bos, P. Dorenbos, M. Bessodes, D. Gourier, D. Scherman and C. Richard, Nat. Mater., 2014, 13, 418.

23 T. Maldiney, B. Ballet, M. Bessodes, D. Scherman and C. Richard, Nanoscale, 2014, 6, 13970.

24 A. Bessière, S. K. Sharma, N. Basavaraju, K. R. Priolkar, L. Binet, B. Viana, A. J. J. Bos, T. Maldiney, C. Richard, D. Scherman and D. Gourier, Chem. Mater., 2014, 26, 1365. 
25 D. Gourier, A. Bessière, S. K. Sharma, L. Binet, B. Viana, N. Basavaraju and K. R. Priolkar, J. Phys. Chem. Solids, 2014, 75, 826.

26 P. Dorenbos, J. Phys.: Condens. Matter, 2003, 15, 8417.

27 P. Dorenbos, J. Lumin., 2005, 111, 89.

28 P. Dorenbos, J. Electrochem. Soc., 2005, 152, H107.

29 P. Dorenbos, J. Mater. Chem., 2012, 22, 22344.

30 P. Dorenbos, J. Lumin., 2013, 134, 310.

31 F. T. You, A. J. J. Bos, Q. F. Shi, S. H. Huang and P. Dorenbos, Phys. Rev. B: Condens. Matter Mater. Phys., 2012, 85, 115101.
32 A. J. J. Bos, P. Dorenbos, A. Bessière and B. Viana, Radiat. Meas., 2008, 43, 222.

33 Y. Zhuang, Y. Katayama, J. Ueda and S. Tanabe, Opt. Mater., 2014, 36, 1907.

34 J. Xu, S. Tanabe, A. D. Sontakke and J. Ueda, Appl. Phys. Lett., 2015, 107, 081903.

35 A. Ikesue, K. Kamata and K. Yoshida, J. Am. Ceram. Soc., 1995, 78, 2545.

36 P. Samuel, G. A. Kumar, T. Yanagitani, H. Yagi, K.-I. Ueda and S. M. Babu, Opt. Mater., 2011, 34, 303. 